\title{
Seismic Moment, Stress, and Source Dimensions for Earthquakes in the California-Nevada Region ${ }^{1}$
}

\author{
Max Wyss and James N. Brune \\ Seismological Laboratory, California Institute of Technology \\ Pasadena, California 91105
}

\begin{abstract}
The source mechanism of earthquakes in the California-Nevada region was studied using surface wave analyses, surface displacement observations in the source region, magnitude determinations, and accurate epicenter locations. Fourier analyses of surface waves from thirteen earthquakes in the Parkfield region have yielded the following relationship between seismic moment, $M_{0}$ and Richter magnitude, $M_{L}$ : $\log M_{0}=1.4 M_{L}+17.0$, where $3<M_{L}<6$. The following relation between the surface wave envelope parameter $A R$ and seismic moment was obtained: $\log M_{0}=\log A R_{\text {soo }}+20.1$. This relation was used to estimate the seismic moment of 259 additional earthquakes in the western United States. The combined data yield the following relationship between moment and local magnitude: $\log M_{0}=1.7 M_{L}+15.1$, where $3<$ $M_{L}<6$. These data together with the Gutenberg-Richter energy-magnitude formula suggest that the average stress multiplied by the seismic efficiency is about 7 bars for small earthquakes at Parkfield and in the Imperial Valley, about 30 bars for small earthquakes near Wheeler Ridge on the White Wolf fault, and over 100 bars for small earthquakes in the Arizona-Nevada and Laguna, Salada (Baja California) regions. Field observations of displacement associated with eight Parkfield shocks, along with estimates of fault area, indicate that fault dimensions similar to the values found earlier for the Imperial earthquake are the rule rather than the exception. for small earthquakes along the San Andreas fault. Stress drops appear to be about $10 \%$ of the average stress multiplied by the seismic efficiency. The revised curve for the moment versus magnitude further emphasizes that small earthquakes are not important in strain release and indicate that the zone of shear may be about $6 \mathrm{~km}$ in vertical extent for the Imperial Valley and even less for oceanic transform faults.
\end{abstract}

\section{INTRODUCTION}

Recent developments have greatly improved our understanding of the mechanism of shallow earthquakes in the California-Nevada region. Many of these earthquakes are strike slip and are related tectonically to the San Andreas fault system. In this paper seismic moments of these earthquakes with local magnitudes between 3 and 6 have been obtained in two ways. First, spectral densities of the surface waves were obtained for thirteen earthquakes from the San Andreas fault system which covered the mentioned magnitude interval about evenly. The moments were computed by means of the theoretical results of Ben-Menahem and Harkrider [1964] and Anderson and Harkrider [1968]. To estimate the seismic moment for a large number of earthquakes without the time-con-

\footnotetext{
${ }^{1}$ Contribution 1513, Division of Geological Sciences, California Institute of Technology, Pasadena, California.
}

suming and costly process of digitizing and Fourier-analyzing the surface waves, the parameter $A R$, as defined by Brune et al. [1963], was used to estimate seismic moment for another 259 shocks from the western United States recorded at Pasadena.

For the eight Parkfield shocks for which spectral densities were determined by Fourier analyses, field observations allowed an estimate of the average relative displacement accompanying them. These observations were obtained in the course of the extensive study of the Parkfield 1966 earthquake sequence. In four cases the relative displacements were recorded on strain meters straddling the surface fault trace; in three other cases repeated measurements of the displacement of the white line on Highway 46 near Cholame were used; in another case the displacement was determined by small-scale geodetic measurements. The details of these investigations are described by Smith and Wyss [1968]. Accurate determinations of the epicenters of these eight shocks 


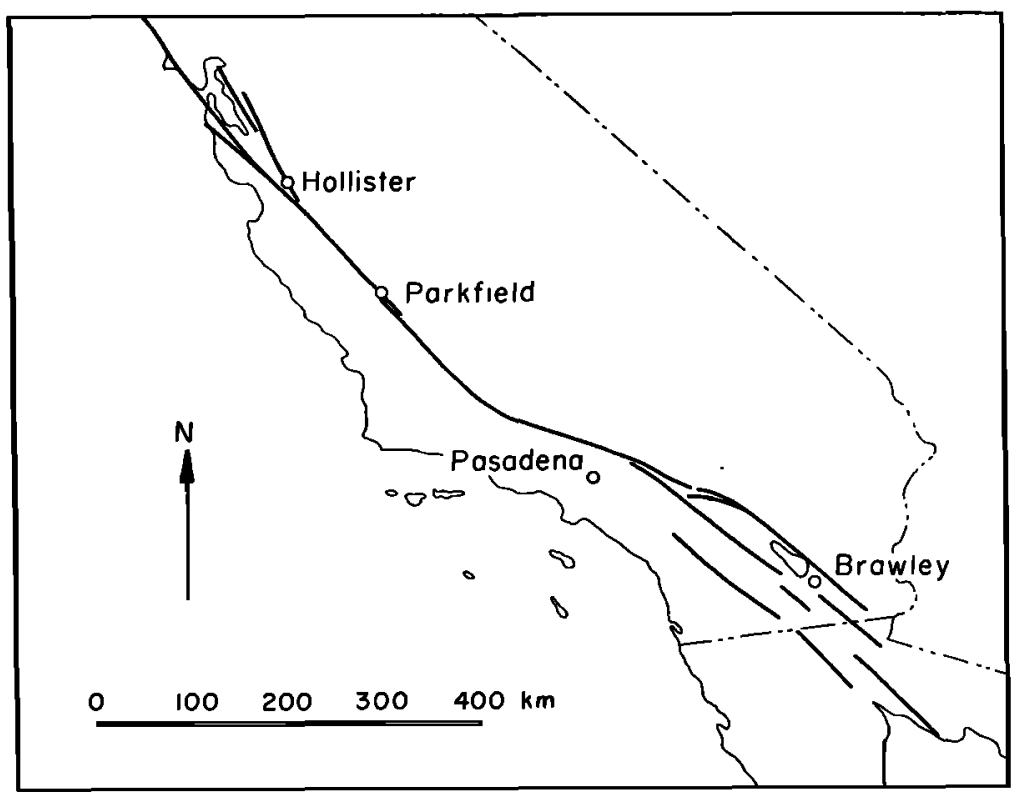

Fig. 1. Map of California showing the San Andreas and related faults. Earthquakes from the regions near Hollister, Parkfield, and Brawley were used for the surface wave Fourier analysis in the present study.

were also available. The distance from the epicenter to the locality where the surface displacement associated with a shock was observed can be considered a minimum value for the fault length of that particular event. Based on these field observations and the surface wave analyses, it has been possible to estimate roughly the fault offset, fault dimensions, stress drop, and average stress.

Basic to the understanding of the mechanics of faulting is the dislocation theory of Maruyama [1963]. Dislocations are related to stress drop by the results of Starr [1928], Knopoff [1958], and Keylis-Borok [1959]. Aki [1966] combined these theoretical studies to interpret earthquake mechanism in a study of the Niigata earthquake and later in a study of the Parkfield earthquake [Aki, 1967]. In the 1967 study Aki proposed a scaling law for seismic spectrum with a decrease in amplitude proportional to $1 / \omega^{2}$ at frequencies higher than some characteristic frequency dependent on magnitude.

The stress drop was found by Aki to be 125 bars for the Niigata earthquake and 0.6 bar for the Parkfield earthquake. Brune and Allen. [1967] found a stress drop of 1.1 bars for the
Imperial earthquake of March 4, 1966. The fault length was about $35 \mathrm{~km}$ for the Parkfield earthquake and about $10 \mathrm{~km}$ for the Imperial earthquake. The results for the Parkfield and Imperial earthquakes indicated that previous suppositions about fault length versus magnitude and stress drop versus magnitude [Press, 1967] would have to be modified. They also indicated that a single scaling law, such as that proposed by $A k i$ [1967], could not be valid for all regions of the earth. Tsuboi [1956] and Bath and Duda [1964] showed that Benioff's $[1951 a, b, 1955]$ earlier assumption that earthquake volume was independent of magnitude was not valid. For large earthquakes $(M>6)$ Bath and Duda found that earthquake volume was approximately proportional to magnitude and the stress prior to earthquakes was approximately independent of magnitude in agreement with Tsuboi's hypotheses. Chinnery [1964] pointed out that the stress drops for most large earthquakes were about 100 bars and suggested that this indicated the limiting strength of the earth's crust was about 100 bars. The low stress drops found for the Parkfield and Imperial shocks suggested that the stress drop for these earthquakes was only a fraction of 
the total stress, as in the stick-slip faulting mechanism of Brace and Byerlee [1966]. Burridge and Knopoff [1964] gave equations relating the energy release to the ratio of the stress drop to the initial stress. Earlier, Orowan [1960] had shown that, if the final stress after rupture was equal to the frictional stress during rupture, studies of the energy of seismic wave radiation did not determine the pre-stress.

King and Knopoff [1968a] correlated the product of fault length and the square of displacement versus magnitude and found that for earthquakes the fractional stress drop decreased with decreasing magnitude; i.e., for small magnitudes this stress drop was a small fraction of the pre-stress.

Burridge and Knopoff [1967] and King and Knopoff [1968b] used a model of earthquake strain release consisting of masses and springs in series. Many of the features of earthquakes occurrence were explained by this model. The results for fault length, fault displacement, and stress drop found in the present study for earthquakes along the San Andreas fault are in approximate agreement with the results from the Parkfield and Imperial earthquakes and with the fractional stress-drop curves suggested by King and Knopoff [1968a].

\section{Moment Versus Magnitude Curve, $3<M<6$}

Seismic moment as a function of magnitude was first estimated by Brune [1968] in order to calculate rates of slip along major fault zones. The moments of a number of large earthquakes were estimated from field observations [Brune and Allen, 1966]. A theoretical curve based on the amplitudes of 100-sec mantle waves [Brune and King, 1967] was fitted through these data. For magnitudes less than 6 no reliable data were available for long-period waves, and as a first approximation it was assumed that the local earthquake magnitude corresponded to the surface wave magnitude. Seismic moments for only two earthquakes below magnitude 6 (Parkfield and Imperial) were available at that time. We here establish more accurately the portion of the momentmagnitude curve for $M_{L}<6$. Surface waves from thirteen earthquakes in the magnitude range from 3.2 to $\mathbf{5 . 5}$ were Fourier-analyzed. All of them were located in the San Andreas fault region with the exception of one shock from the southern Gulf of California. The epicenters were obtained from J. Eaton (personal communication), McEvilly et al. [1967], and Richter et al. [1967]. When the magnitude assigned by the latter two sources differed, the average was taken. For the surface wave analysis Press-Ewing seismograms from the Pasadena station were used. In Table 1 the origin time, depth, and magnitude of these shocks are given. Considerations of the uncertainties in the magnitude determinations, instrumental corrections, local geologic conditions, etc., suggests that in this experiment an uncertainty of a factor of 2 in relating moment to magnitude might be expected. In the future this uncertainty can be further reduced by use of more stations close to the source. The present study has the advantage that the station used (Pasadena) is also the station originally used to define the various magnitude scales.

The equivalent double-couple seismic moment, as defined in the dislocation theory of faulting [Maruyama, 1963], was obtained from surface wave spectral density observed at Pasadena. The procedure is essentially that used by $A k i$ [1966]. The far-field displacement for a double couple as given by Ben-Menahem and Harkrider [1964] was used to obtain moment from spectral density.

The fault plane solution for the Parkfield earthquakes was given by $M c E v i l l y$ et al. [1967]; that for the Gulf of California earthquake was given by Sykes [1968]. Shocks 4 and 11 of Table 1 were assumed to have originated on the San Jacinto and Imperial faults, respectively, and the approximate direction of the fault plane for shock 3 was obtained from the CIT southern California array. The thirteen analyzed shocks are very close to vertical strike-slip faults. All the shocks are shallow. For vertical strike-slip faults at a shallow depth Ben-Menahem and Harkrider's expression for Love waves simplifies to:

$$
M_{0}=\left(r C_{L} T\right)^{1 / 2}\left(\tilde{U}_{\theta} \omega / A_{L} \cos 2 \theta\right)
$$

where $r$ is the distance, $C_{L}$ is the Love wave phase velocity, $\widetilde{U}_{\theta}$ is the spectral density, $\theta$ is the azimuth from the strike of the fault to the station, $A_{L}$ is the excitation function defined by Harkrider [1964], and $\omega=2 \pi / T$ is the angular frequency. For $A_{L}(t)$ the values for a tectonic 


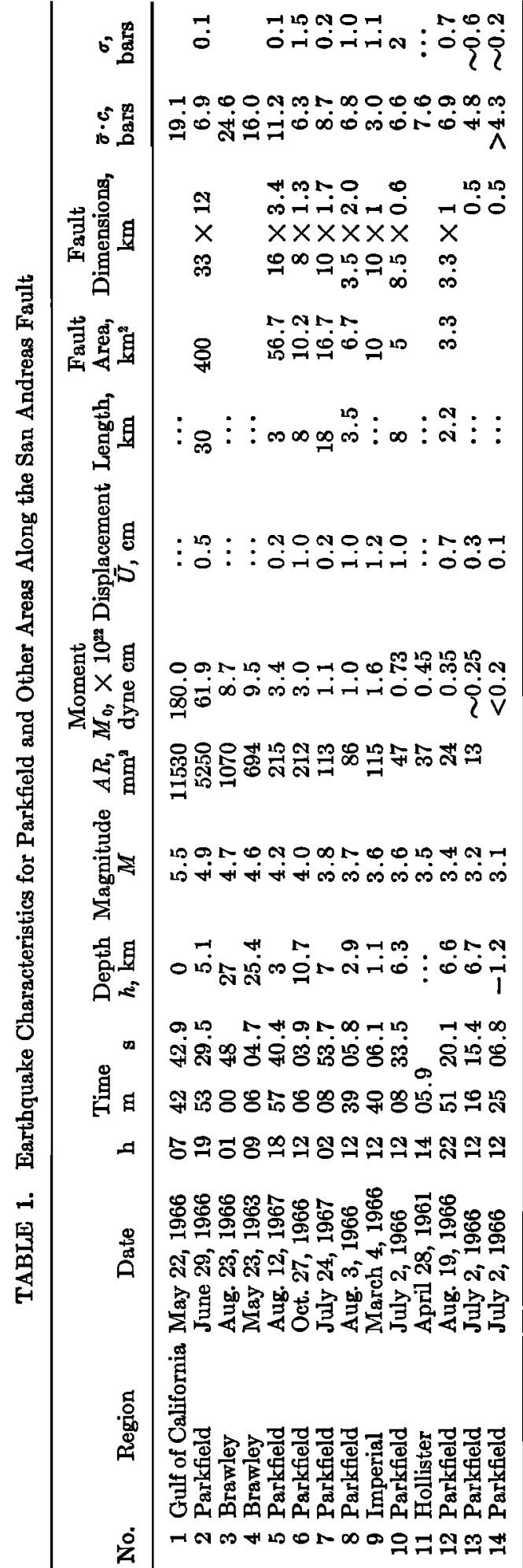

model given by Anderson and Harkrider [1968] were used.

The surface waves of shock 8 recorded at Pasadena by 30-90 Press-Ewing instruments are shown in Figure 2. After resolving into transverse and longitudinal components, the Love waves were Fourier-analyzed. Three values for moment were obtained for each shock, using three spectral density values around the peak density ( $T \approx 20 \mathrm{sec}$ ). The average moments for these three determinations are given in Table 1 and are plotted as solid circles in Figure 3. Shocks 3 and 4 lie somewhat below the fitted line. Their hypocenters were deeper than the hypocenters of the other shocks, and it is not certain that their motion was strike slip.

The double circled point at magnitude 6 (Figure 3) was obtained from the Gutenberg definition of surface wave magnitude $M$. [Richter, 1958]. According to the definition, a magnitude 6 earthquake produces a far field displacement of $100 \mu$ at a distance of $22^{\circ}$ for surface waves of 20 -sec period. From this amplitude the moment was calculated. This point thus represents the average of the numerous observations on which the surface wave magnitude was based. As pointed out by Richter $[1958$, p. 347$]$, the scale was adjusted to agree with the local magnitude $M_{\Sigma}$ for magnitude values of 6 to 7 .

The logarithms of the moments of these thirteen earthquakes closely define the following moment-versus-magnitude relation:

$\log M_{0}=1.4 M_{L}+17.03<M_{L}<6(2)$

U

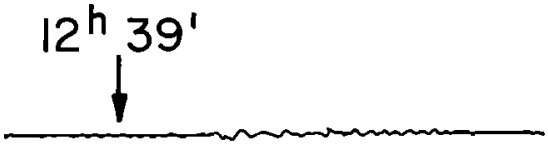

D

$N$

S

E

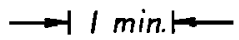

Fig. 2. Shock $8, M=3.7$, Parkfield, recorded by three component long-period Press-Ewing seismographs at Pasadena. 


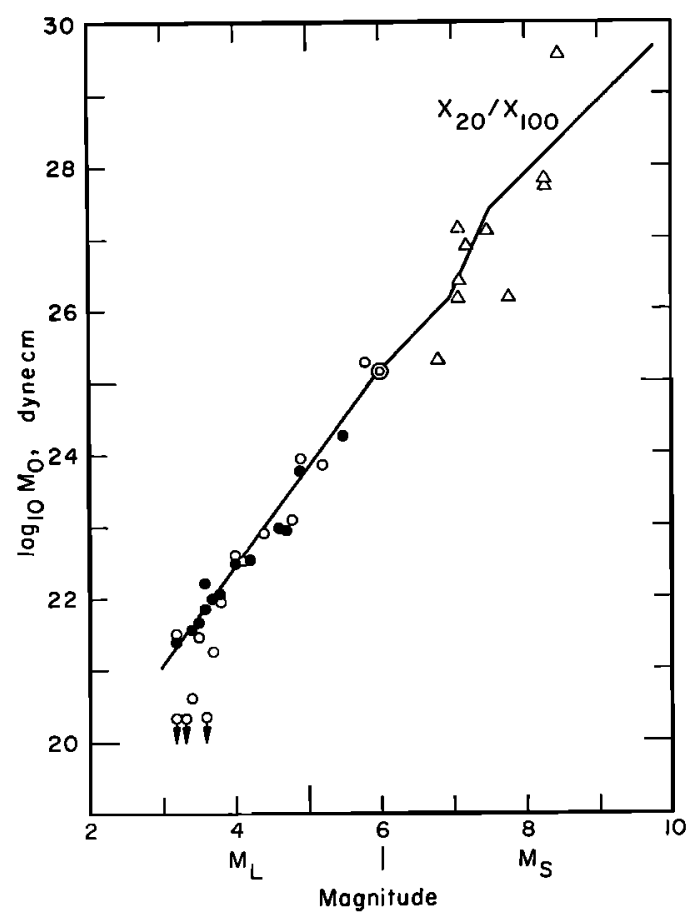

Fig. 3. Log of seismic moment as a function of magnitude for shocks along the San Andreas fault. After Brune [1967], modified for $M_{L} \leq 6$. The solid circles represent the shocks listed in Table 1. Moments derived from the parameter $A R$ are represented by open circles, and moments estimated from field evidence are represented by open triangles. The slope of the straight line below $M=6$ is 1.4 .

The slope of this line indicates that in the magnitude range $3<M_{L}<6$ the seismic efficiency $c$ is not a rapidly varying function of magnitude. This follows from the energymagnitude relation given by Richter [1958]

$$
\log E_{S}=a+b M
$$

and the relationship for work done during a dislocation

$$
E=\bar{\sigma} A \bar{U}=\bar{\sigma} M_{o} / \mu
$$

In these equations $E_{S}$ is the seismic energy, $E$ is the elastic energy, $M$ is the magnitude, $\bar{\sigma}$ is the average acting stress (average of the initial and the final stress), $A$ is the fault plane area, $\bar{U}$ is the mean relative displacement on the fault plane associated with an earthquake, $M_{0}$ is the seismic moment, and $\mu$ is the shear modulus. Let $c$ be the seismic efficiency factor; then

$$
E_{S}=c E
$$

Combining (3), (4), and (5) gives the magnitude as a function of moment.

$$
M=\frac{1}{b}\left[\log M_{0}+\log (\bar{\sigma} c)-(\log \mu+a)\right]
$$

Thus $b$ is the slope of the log moment versus magnitude curve if $c$ is not a function of magnitude. The observed value of the slope of $M_{0}$ versus magnitude is $\mathbf{1 . 4}$ and thus is close to the value of $b=1.5$ for the Gutenberg-Richter relation, suggesting that $c$ is not critically dependent on magnitude in the small range of magnitudes considered here. From the Gutenberg-Richter energy relation

$$
\log E_{s}=1.5 M+11.8
$$

Letting $\mu=3 \times 10^{11}$, we can solve equation 6 for the product of the average stress and efficiency, $\bar{\sigma} c$. For the nine Parkfield shocks in Table 1 the result is

$$
\bar{\sigma} c=7.3 \pm 1.8 \mathrm{bar}
$$

The error is the mean deviation for the nine analyzed shocks. Equation 6 suggests that the deviations from a single moment versus magnitude relation can reflect, among other things, local differences in the average stress.

\section{Data from Other Regrons Based on $A R$}

In a paper by Brune et al. [1963] the parameter $A R$, the sum of the area of the envelopes of the surface waves on three component longperiod Press-Ewing instruments, was used as a measure of the long-period waves. $A R$ is approximately proportional to spectral density and thus to seismic moment. If the relation of $A R$ to moment is established, one can approximately convert $A R\left(\mathrm{~mm}^{2}\right)$ into spectral density and thus into seismic moment. The relationship was established by determining $A R$ for the thirteen analyzed shocks and plotting these values against seismic moment. The result is shown in Figure 4. This relation is valid for shocks not exceeding depths of about 20 $\mathrm{km}$. As expected, the points fall closely along a straight line with a slope of 1 . The conversion equation is

$$
\log M_{0}=\log A R_{300}+20.1
$$

where $A R_{300}$ is the sum of the surface wave 


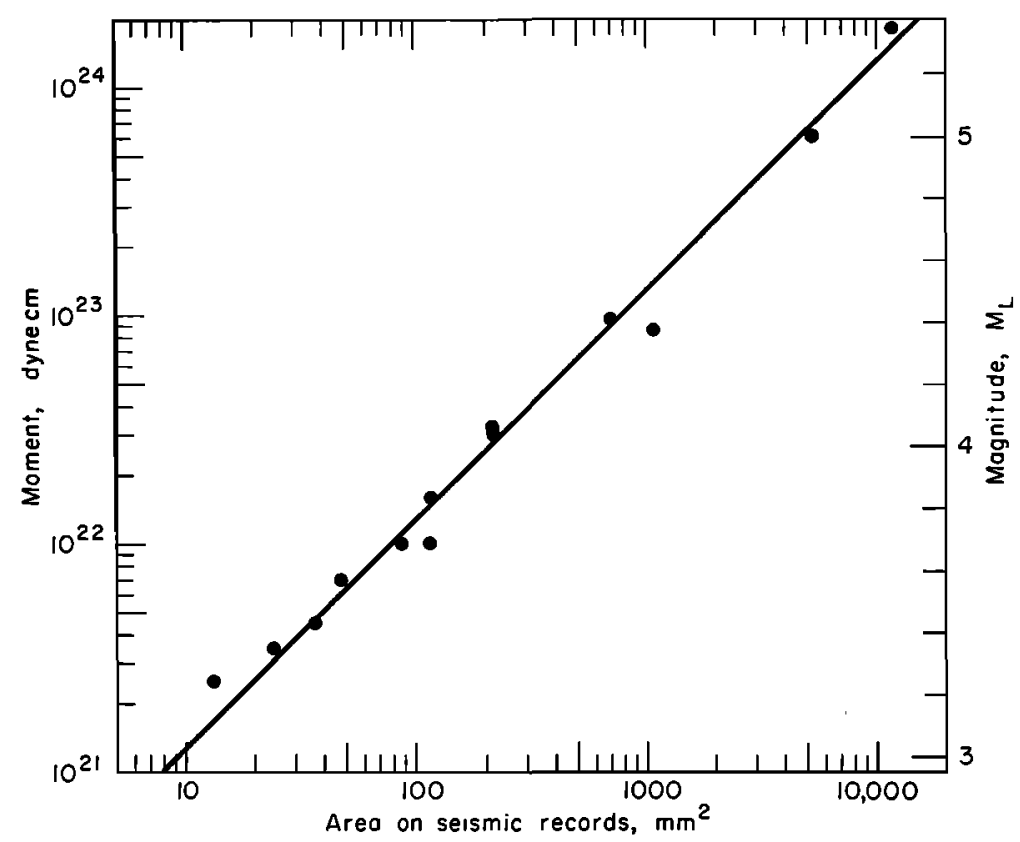

Fig. 4. Moment as a function of surface wave envelope area $A R$ corrected to a distance of $300 \mathrm{~km}$. The data points are derived from the shocks listed in Table 1. This curve can be used to approximately convert $A R$ into moment.

envelope areas normalized to a source distance of $300 \mathrm{~km}$.

This equation was used to obtain the seismic moments for seventy-seven shocks whose $A R$ values at Pasadena were determined by Brune et al. [1963] as well as for 182 additional shocks. The results are shown in Figure 5. Shocks from the San Andreas and San Jacinto faults and from the Imperial Valley and Gulf of California are shown as solid circles. Squares represent shocks from off the coast of California; open circles represent shocks from Nevada, Arizona, Utah, Baja California, and northern California. For these earthquakes the fault plane orientations are not known and the depth is uncertain. The scatter is considerable. As pointed out in Brune et al. [1963], however, a grouping of shocks for various regions can be observed. The Gulf of California shocks give moments that are somewhat smaller on the average than the San Andreas values, but, since they are not much different, the same symbol was used. The shocks from off the coast of northern California have higher $M_{0}$ values than shocks of the same magnitude from the San Andreas. This similarity may in part be due to a strong filtering of short- period body waves at the continental margin, which could make the body wave magnitude smaller. The Nevada-Arizona as well as the Baja California earthquakes fall below the San Andreas values. If it is assumed that these regional differences in surface wave excitation are due to regional differences in stress, we can solve for $\bar{\sigma} c$ by fitting a line with a slope of 1.4 through the data for each region. This yields a value of $\bar{\sigma} c$ of about 110 bars for the Laguna Salada (Baja California) and California Nevada earthquakes. The regional variations observed here could also be due to path effects, depth of source, and variations in faulting mechanism. However, the surface wave paths for all analyzed earthquakes are short $(\Delta \leq 1000 \mathrm{~km})$ and similar. All events were shallow, most of them not exceeding $16 \mathrm{~km}$ depth. The $A R$ method of determining the seismic moment, adding Rayleigh and Love wave envelopes, averages out the differences caused by different faulting mechanisms. Therefore, it is very likely that the regional variations in seismic moment are in part due to variations in tectonic stress. The relatively low stresses along certain sections of the San Andreas fault may in part be caused 


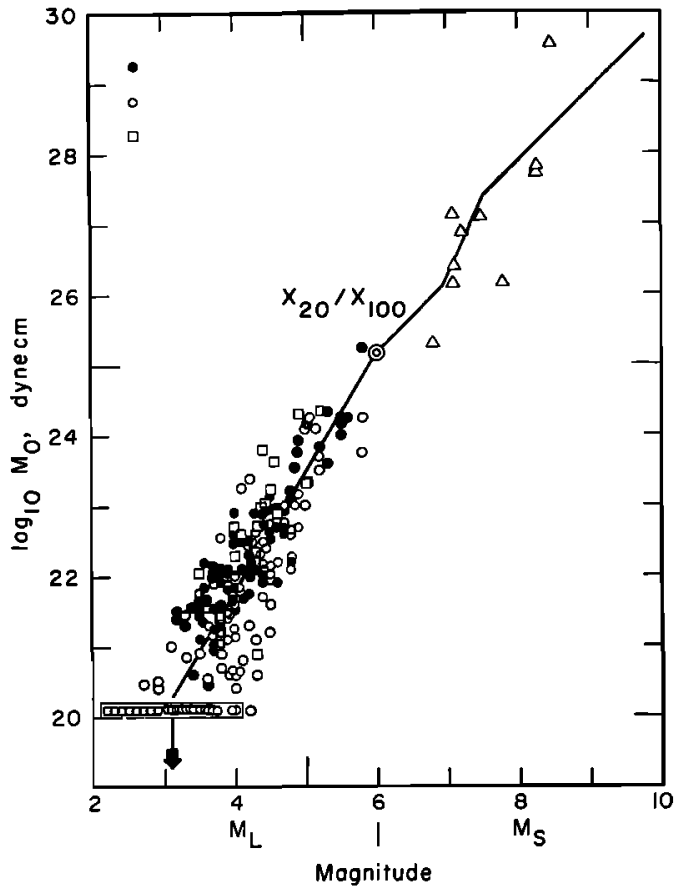

Fig. 5. Logarithm of seismic moment as a function of magnitude with data from the westernmost part of the United States. The slope of the straight line through the data is 1.7. Solid circles indicate San Andreas fault system; open circles, western United States; squares, region off the coast of California.

by geologic and tectonic features that control the amount of stress the crust can withstand [Allen, 1968].

The straight line that was fitted through all the available data for moment versus magnitude for the western United States (Figure 5) gives the equation

$$
\log M_{0}=1.7 M_{L}+15.1 \quad 3<M_{L}<6
$$

\section{RELATTONSHIPS BETWEEN $M_{L}$ AND $M_{s}$}

Since the surface wave magnitude $M_{s}$ is based on the amplitude of 20 -sec surface waves and our results for moment are also based on the amplitudes of 20 -sec surface waves, we can get the relationship between surface wave magnitude $M_{\triangle}$ and local earthquake magnitude $M_{L}$ from the straight lines shown in Figures 3 and 5 . These relationships are

\section{Western United States}

$$
\begin{aligned}
& M_{S}=1.7 M_{L}-4.1 \quad 3<M_{L}<6 \\
& \text { Parkfield }
\end{aligned}
$$

$$
M_{S}=1.4 M_{L}-2.2 \quad 3<M_{L}<6
$$

and are valid for very shallow earthquakes. These equations are in qualitative agreement with the statements given by Richter [1958, p. 347]. He indicates that, although the local earthquake magnitude and the surface wave magnitudes were originally constructed to be in agreement between magnitudes 6 and 7, later investigations indicated that for lower magnitudes the surface wave magnitudes are smaller than the local magnitude, in agreement with equations 11 .

\section{Field Observations of Fault Displacement}

For the nine shocks that occurred in the Parkfield region, fault slip was measured in the field. The approximate average slip is given in Table 1. The detailed nature of the field evidence for each shock is given below.

For shock $2(M=4.9)$ the offset of the white line on Highway 46 near Cholame (Figure 6) was measured repeatedly after the Parkfield earthquake of June 20, 1966 [Smith and Wyss, 1968]. On June 29 it was measured at

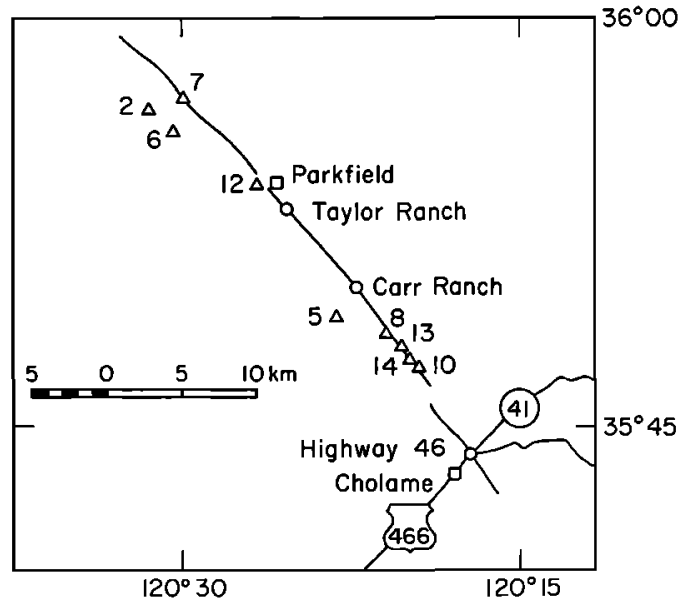

Fig. 6. Map of the Parkfield region. The surface break connected with the Parkfield earthquake of 1966 is shown as a solid line. Surface observations concerning fault slip were obtained at the Taylor ranch, the Carr ranch, and Highway 46. Epicenters of shocks for which surface displacement was observed are marked by triangles and numbered according to Table 1 . 


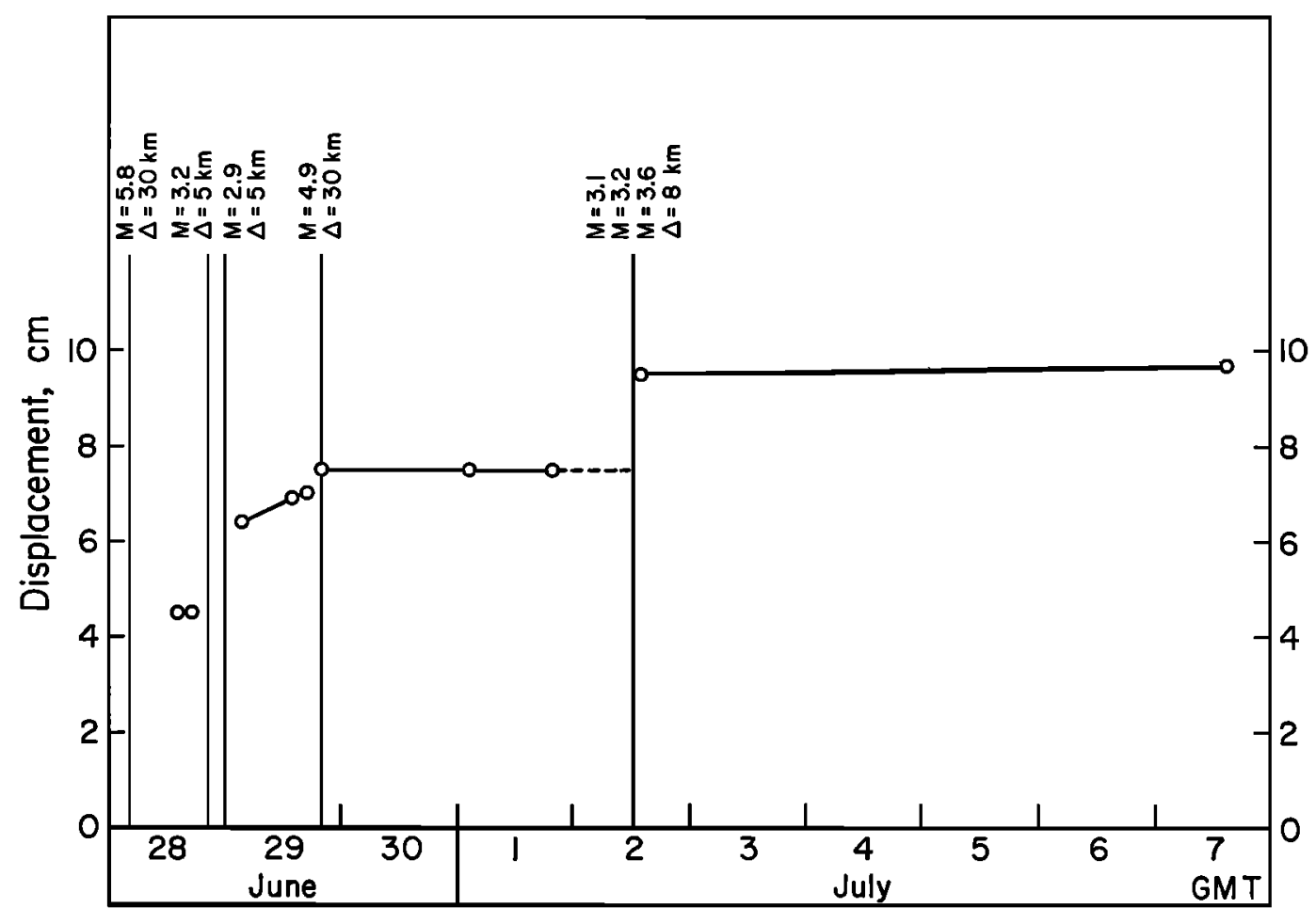

1966

Fig. 7. Evidence for fault slip. The displacement of the white line at Highway 46 following the Parkfield earthquake on June 28, 1966, is compared with the occurrence of aftershocks. Shock 2 is believed to have caused a slip of $0.5 \mathrm{~cm}$ on June 29. Shocks 10, 13, and 14 are believed to have caused a slip of $1.5 \mathrm{~cm}$ on July 2 .

$14 \mathrm{~h} 00 \mathrm{~m}, 17 \mathrm{~h} 00 \mathrm{~m}$, and $20 \mathrm{~h} 00 \mathrm{~m}$ GMT. In the 3 -hour time interval, whose end preceded shock 2 by about 3 hours, no displacement was observed within the accuracy of measurement. In the 3-hour time interval that contained the earthquake and terminated about 7 min after the shock $0.5 \mathrm{~cm}$ of displacement was observed (Figure 7). Three subsequent measurements about 31,43 , and 48 hours after the shock showed no further displacement. From this evidence we may conclude that the offset of $0.5 \mathrm{~cm}$ that occurred between $12 \mathrm{~h} 00 \mathrm{~m}$ and $20 \mathrm{~h} 00 \mathrm{~m}$ GMT was associated with the earthquake that occurred at $19 \mathrm{~h} 53 \mathrm{~m} 29.5 \mathrm{~s}$ GMT north of Parkfield. The location of the epicenter lies $30 \mathrm{~km}$ northwest along the San Andreas fault from the place where the displacement was observed. Therefore this shock must have had a fault length of at least $30 \mathrm{~km}$.

For shocks 5 and 7 ( $M=4.2$ and 3.8 , respectively) creep was measured subsequent to its occurrence by an Invar wire strain meter installed across the fault at the Carr ranch [Smith and Wyss, 1968]. The shocks indicated in Figure 8 and no others were reported as felt at the Carr ranch. Although the displacements started somewhat after the shocks and took about 5 days to accumulate, it seems reasonable that they were related to the earthquakes. Presumably the displacement that took place at the time of the shocks at depths of 3 and $2 \mathrm{~km}$, respectively, strained the overlying layers of sediments that responded by creep. Since little is known about the creep mechanism, the displacement observed at the surface is, as a first approximation, assumed to be equal to the average displacement that occurred along the fault plane at depth during the earthquake. This displacement was $0.2 \mathrm{~cm}$ in both cases.

Similar arguments apply to shocks 8 and 12 . The creep displacements that followed these 


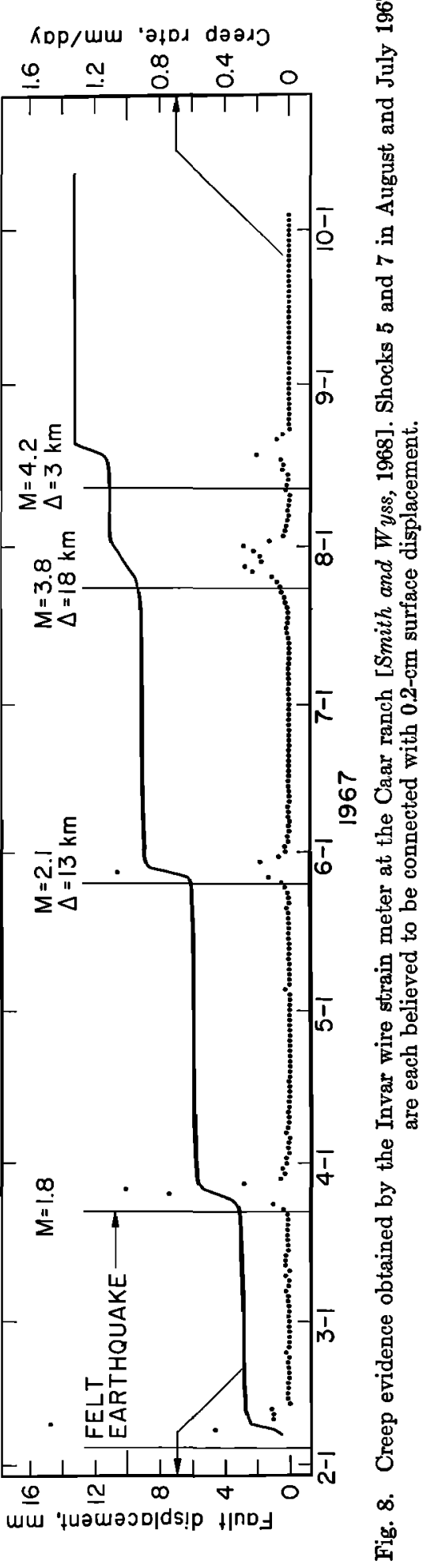

shocks were also measured at the Carr ranch. At this time the quartz strain meter was in operation. The total creep displacements were $1.0 \mathrm{~cm}$ and $0.7 \mathrm{~cm}$, respectively (Figure 9 ).

Shocks 10,13, and 14 occurred in short sequence close to each other with epicenters $8 \mathrm{~km}$ north of Highway 46. The white line at Highway 46 showed no displacement for a 2 -day period ending at $20 \mathrm{~h} 00 \mathrm{~m}$ on July 1 . The shocks 10,13 , and 14 occurred at $12 \mathrm{~h} 09 \mathrm{~m}$, $12 \mathrm{~h} 16 \mathrm{~m}$, and $12 \mathrm{~h} 25 \mathrm{~m}$ on July 2 . The first measurement afterward was taken at $14 \mathrm{~h} 00 \mathrm{~m}$ on July 2 and revealed an added displacement of $1.5 \mathrm{~cm}$ (Figure 7).

Shock 6 seems to have been responsible for a displacement of about $1 \mathrm{~cm}$ at the Taylor Ranch [Smith and Wyss, 1968]. The cumulative displacement at this locality preceding the time of earthquake 6 followed a logarithmic curve given by the equation

$$
U=9.4 \log t-4.5
$$

where $U$ is cumulative relative displacement in centimeters and $t$ is time in days (Figure 10). The displacement of about $1 \mathrm{~cm}$ on November

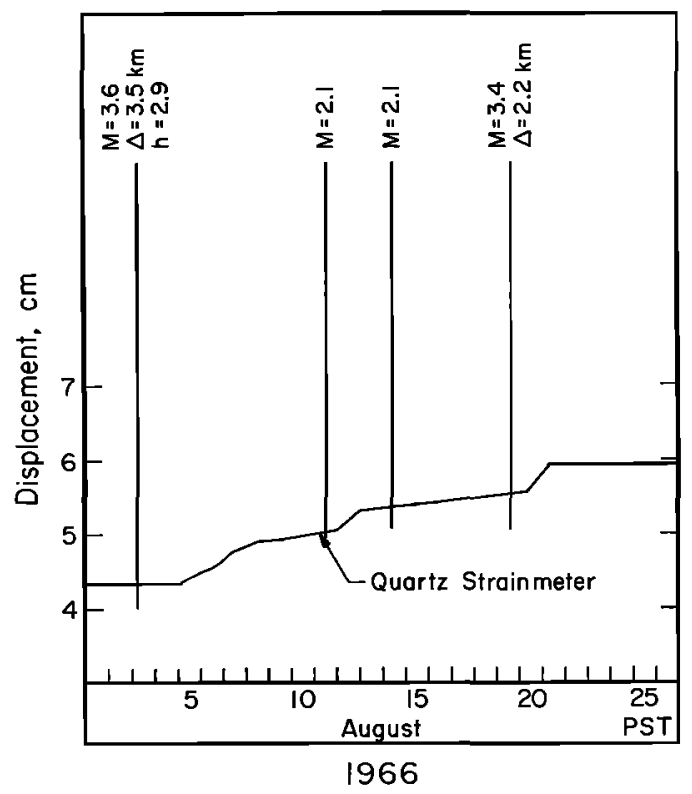

Fig. 9. Creep evidence obtained by the quartz strain meter at the Carr ranch [Smith and Wyss, 1968]. Shocks 8 and 12 are believed to be connected with 1.0- and 0.7-cm surface displacement on August 3 and August 19, respectively. 


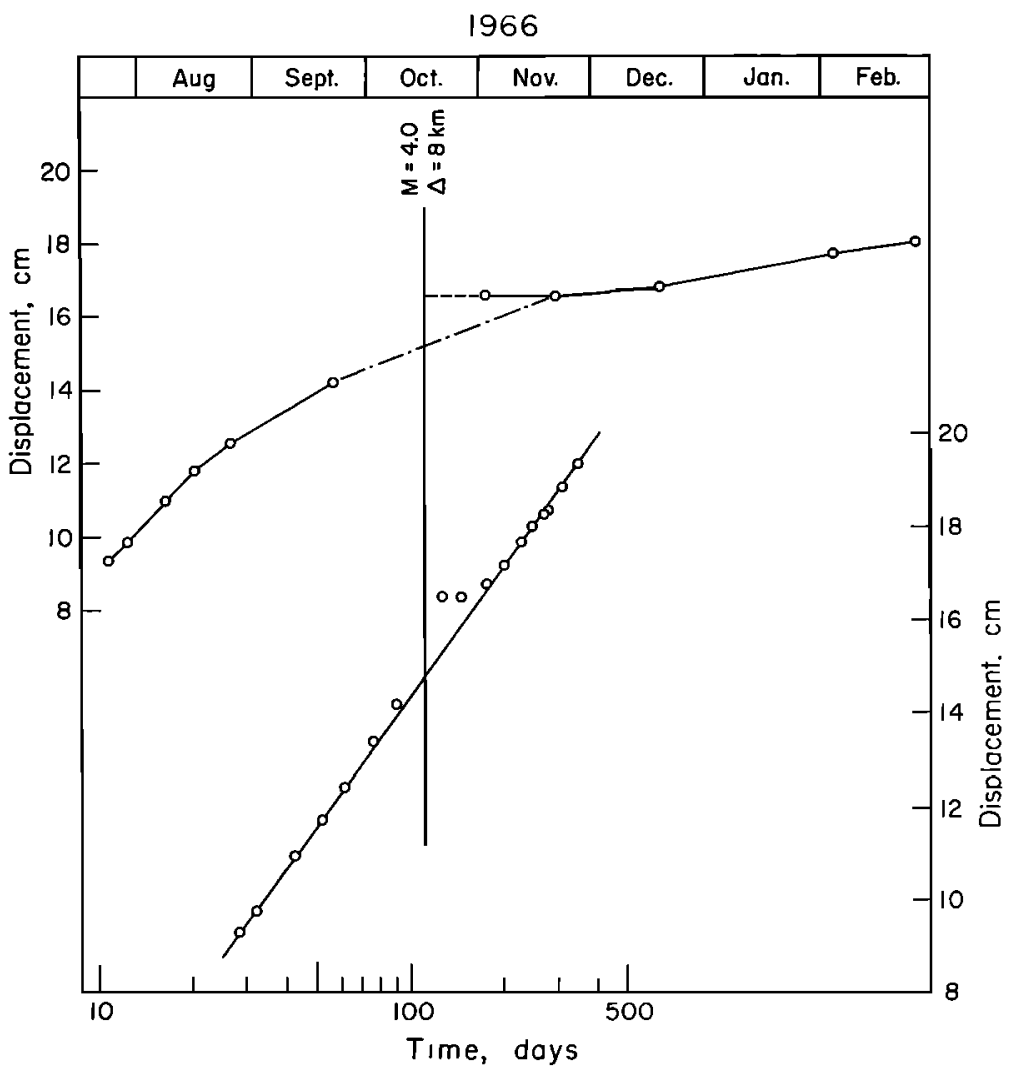

Fig. 10. Displacement evidence obtained by small-scale geodetic observations at the Taylor ranch [Smith and Wyss, 1968]. The upper curve represents displacement as a function of time; the lower one, the same displacement as a function of log time. The displacement connected with shock 6 is estimated to be about $1 \mathrm{~cm}$.

3,1966 , was followed by a period of no displacement up to November 22. After this date the displacement values continued to follow the same logarithmic curve as before. Shock 6 on October 27 was located at a distance of 8 $\mathrm{km}$ to the northwest of the Taylor ranch. In the same interval of time between geodetic measurements three shocks of magnitude 2 to 2.3 occurred [McEvilly et al., 1967].

It is concluded from the above evidence that as a first approximation it may be assumed that the surface displacements (including creep) associated with each earthquake are representative of the displacements that occurred at depth during the respective earthquakes.

\section{Source Dimensions}

For the nine shocks that occurred in the Parkfield area field evidence for approximate relative displacement was listed above. For the same shocks the seismic moment was obtained from surface wave analysis and equation 1 . The fault area was obtained from the equation

$$
M_{0}=\mu A \bar{U}
$$

The values are given in Table 1. A value of $3 \times 10^{11}$ dynes $/ \mathrm{cm}^{2}$ was assumed for $\mu$ except for the very shallow shocks $9,10,12,13$, and 14 for which a value of $1.5 \times 10^{11}$ dynes/ $\mathrm{cm}^{2}$ was assumed. Where the field evidence also yielded an estimate for the fault length and fault width a check on the above estimate of area was provided. The epicentral distances to the points where the respective displacements were observed are listed in Table 1 as fault length. Regarding this value as a minimal fault length and the assigned depth as a minimal fault width for the cases of surface rup- 
ture, dimensions consistent with the fault area computed from the moment and surface offset are proposed and also given in Table 1 . The locations of shocks $2,5,6$, and 7 were obtained from McEvilly et al. [1967]; the locations of shocks 8, 10,13, and 14, from J. Eaton (personal communication); the location for shock 12 was taken from the Pasadena Local Bulletin [Richter et al., 1967]. During the months following the Parkfield earthquake a number of portable seismic stations were operated in the area; hence, the epicenters for this period were determined very accurately. The source dimensions derived from surface wave analyses and measurements of ground displacement in the field are consistent with the fault lengths estimated from the epicentral distances to the sites of measurement. These results strongly suggest that the proposed source dimensions are approximately correct.

The fault lengths as proposed in Table 1 were compared with the magnitude versus length plot by Press [1967]. The results are shown in Figure 11 as open triangles. These values are interesting for the geologist since they approximate actual surface rupture length. They may also be compared with other data obtained by field evidence (solid triangles) taken from King and Knopoff [1968a].

If the square root of the fault plane area (solid circles) is plotted rather than the fault length, the following approximate relation is found:

$$
M=1.9 \log A^{1 / 2}-6.7
$$

Substituting equation 7 into equation 14, we obtain

$$
\begin{aligned}
E_{S}=2.5 \times 10^{2} \times A^{1.43} & \\
& =2.5 \times 10^{2} \times L^{2.86}
\end{aligned}
$$

This relation indicates that seismic energy for these small shocks is approximately proportional to the cube of the fault dimension. The straight line fitted by Tocher [1958] through the field observations of surface rupture of large earthquakes suggested a second-power dependence of the elastic energy on fault length.

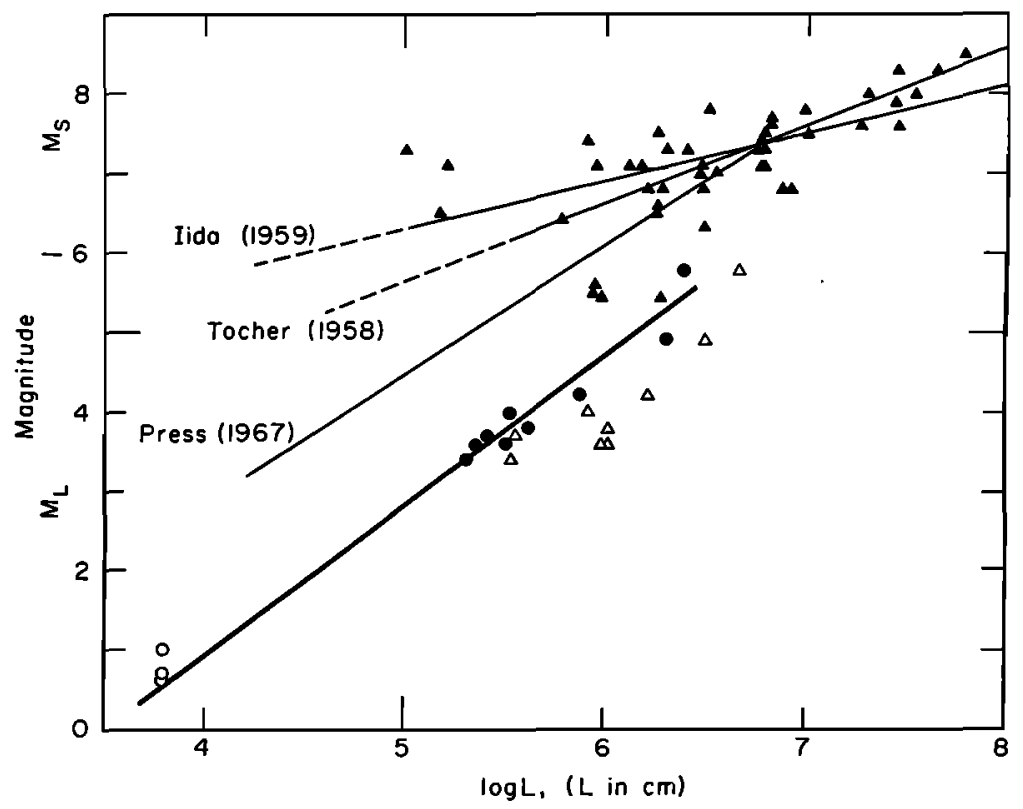

Fig. 11. Observations of fault length plotted as a function of magnitude. For each of nine earthquakes, including the Parkfield mainshock, two points are plotted. The open triangles represent fault lengths estimated from field evidence, and the solid circles represent $(A)^{1 / 2}$ determined from seismic wave analysis and field observations of fault offset. The values for micro-earthquake fault dimensions (open circles) are taken from Smith et al. [1967]. The solid triangles represent fault lengths taken from [King and Knopoff, 1968a]. 
Press's [1967] curve for shocks smaller than about magnitude 7 was constructed with a third-power dependence of elastic energy on source dimension. Our data are in accordance with the results of Smith et al. [1967] for earthquakes of the magnitude range of about 1 (open circles in Figure 11) and suggest that for earthquakes of $0<M_{L}<5$ the thirdpower dependence of the elastic energy on fault length holds.

From Figure 11 it is evident that all the Parkfield earthquakes have source dimensions at least an order of magnitude larger than predicted by Press's curve. Thus, it appears that for small earthquakes along the San Andreas fault large source dimensions such as those found by Brune and Allen [1966] for the Imperial earthquake are quite common. An increase of stress drop, average stress, or efficiency, keeping the source dimension constant, would increase the corresponding magnitude. Thus, Press's curve would apply to earthquakes of greater stress drop, greater average stress, or better efficiency. For very large earthquakes, all these conditions probably apply. Regional variations in surface wave excitation mentioned earlier suggest that in some areas the stresses may be high enough to bring the values of source dimension into agreement with Press's curve.

\section{Stress Drop}

Stress drops for the Parkfield shocks were estimated using the following formula, which applies to an infinitely long vertical surface fault with strike-slip displacement [Knopoff, 1958]:

$$
\sigma=\frac{1}{2} U_{m} \mu / W
$$

where $U^{m}=(4 / 3) \bar{U}$ is the maximum relative displacement and $W$ is the fault width. The values are given in Table 1 . Since the field observations of displacement may not accurately reflect the average displacement, the values for the stress drops should be regarded only as order of magnitude determinations. The average stress drop is approximately 1 bar.

\section{Comparison of Excitation of Surface Waves by Earthouakes and UNderground: Nuclear Explosions}

The excitation of surface waves by earth- quakes of $3<M_{x}<5$ along the San Andreas fault has been found in this study to be much greater than for NTS explosions of equivalent magnitude. These data are in agreement with the earlier results of Brune et al. [1963]. In the earlier study it was possible only to speculate that this was the result of larger source dimensions for earthquakes, but it is now evident that this is indeed the case. Field studies of the Parkfield earthquake and its aftershocks and of the Imperial earthquake have conclusively demonstrated that these earthquakes have much greater source dimensions than previously surmised by Press [1967] and have much greater source dimension than equivalent magnitude explosions. This conclusion is apparently valid for magnitudes at least as low as 3.0 and is thus very important in any consideration of extending the nuclear test ban treaty to underground explosions of low magnitude. It must be cautioned, however, that many earthquakes in the Laguna Salada and Nevada-Arizona regions apparently have much smaller source dimensions and indeed may have source dimensions of the same order as surmised by Press.

\section{Calculated Rates of Slip Along Major Fault Zones}

Brune [1968] calculated the rates of slip along major fault zones by summing the moments for earthquakes in these zones. Modification of the moment versus magnitude curve for $3<M_{L}<6$ according to equation 2 will reduce the calculated rates of slip for the zones in which local magnitudes $M_{L}$ were used, i.e. in the California region where local magnitudes were used for magnitudes as low as 3.0. For other regions either the surface wave magnitude or the body wave magnitude was used, and thus it is not obvious that any correction is necessary. The correction will be most important on zones that did not have large earthquakes.

In the Imperial Valley of California the calculated rate of slip is reduced from 3.2 to $2.2 \mathrm{~cm} / \mathrm{yr}$, and the depth of the shear zone necessary to balance the geodetically observed shear rate of $8 \mathrm{~cm} / \mathrm{yr}$ is reduced from about 8 to about $6 \mathrm{~km}$. The calculated rate of slip for the Kern County, California, region is only slightly reduced, from 17 to $16 \mathrm{~cm} / \mathrm{yr}$, and the 
calculated rate of slip along the San Andreas fault since 1800 is reduced from 6.6 to 6.1 $\mathrm{cm} / \mathrm{yr}$. It should be mentioned here that in this calculation of slip Brune included three earthquakes of magnitude $81 / 4$. The three were the 1812 , 1906, and 1857 earthquakes listed by Richter [1958]. Including the 1812 earthquake in this calculation has raised some objections. If this earthquake is omitted or reduced in magnitude, the calculated slip rate will be reduced from 6.1 to about $5.1 \mathrm{~cm} / \mathrm{yr}$.

\section{Conchusions}

The following relationships between moment $M_{0}$ and local magnitude $M_{L}$ have been found:

Parkfield

$$
\begin{aligned}
& \log M_{0}=1.4 M_{L}+17.0 \quad 3<M_{L}<6 \\
& \text { Western United States }
\end{aligned}
$$

$$
\log M_{0}=1.7 M_{L}+15.1 \quad 3<M_{L}<6
$$

This result indicates that the contribution of small earthquakes to the slip in active tectonic zones is relatively insignificant.

From the Fourier spectral densities of the surface waves used in this study the following relationship between $M_{L}$ and surface wave magnitude $M_{s}$ is derived:

$$
M_{S}=1.7 M_{L}-4.1 \quad 3<M_{L}<6
$$

An approximate relationship for obtaining the seismic moment from the surface wave parameter $A R$ of Brune et al. [1963] has been derived:

$$
\log M_{0}=\log A R_{300}+20.1
$$

Large regional variations in the excitation of long-period surface waves have been interpreted in terms of regional variations in the product of the average stress times the seismic efficiency. This product varies from about 7 bars along the San Andreas fault to over 100 bars in the Laguna-Salada and Nevada-Arizona regions.

Field measurements have yielded approximate estimates of fault offset, length, and width for earthquakes in the Parkfield region. Stress drops of about 1 bar are indicated. This value is about $10 \%$ of the estimated average stress times efficiency. For the seismic efficiency $c=$ 1 this would indicate fractional stress drops of
$10 \%$; for $c=0.1$ the fractional stress drops would be $1 \%$. This result is in approximate agreement with suggestions of King and Knopoff [1968a] and with the stick-slip faulting mechanism of Brace and Byerlee [1966].

Field observations suggest that for Parkfield earthquakes with magnitudes between 3 and 6 fault lengths are of the order of $10^{5}$ to $5 \times$ $10^{\circ} \mathrm{cm}$ and approximately related to magnitude by the following equation:

$$
M_{L}=1.9 \log L-6.7
$$

Thus, the source dimensions for these earthquakes are much larger than for equivalent magnitude explosions. This is the explanation for the relatively greater excitation of surface waves by earthquakes than by explosions of equivalent local magnitude $M_{L}$.

Acknowledgments. We wish to thank Dr. C. R. Allen, who kindly read the manuscript. Special thanks are given to Mrs. Barbara Sloan and Mr. Laszlo Lenches who helped to prepare the manuscript.

This research was supported by National Science Foundation grant GA 1087 and the Air Force Office of Scientific Research, Office of Aerospace Research, United States Air Force, under AFOSR contract $\mathrm{AF}-49(638)-1337$.

\section{REFERENCES}

Aki, K., Generation and propagation of $G$ waves from the Niigata earthquake of June 16, 1964, 2, Estimation of earthquake moment, released energy, and stress-strain drop from $G$ wave spectrum, Bull. Earthquake Res. Inst. Tokyo Univ., 44, 73-88, 1966.

Aki, K., Scaling law of seismic spectrums, J. Geophys. Res., 72, 1217-1231, 1967.

Allen, C. R., The tectonic environments of seismically active and inactive areas along the San Andreas fault system, submitted for publication in Proceedings of the Conference on Geologic Problems of the San Andreas Fault System, Stanford University, September 14-16, 1967, 1968.

Anderson, D. L., and David G. Harkrider Universal dispersion tables, 2, Variational parameters for amplitudes, phase velocity, and group velocity for first four Love modes for an oceanic and a continental earth model, Bull. Seismol. Soc. Am., 59, in press, 1968.

Båth, M., and S. J. Duda, Earthquake volume, fault plane area, seismic energy strain, deformation, and related quantities, Ann. Geofis. Rome, 17, 353-368, 1964.

Benioff, H., Earthquakes and rock creep, 1, Creep characteristics of rocks and the origin of aftershocks, Bull. Seismol. Soc. Am., 41, 31-62, $1951 a$. 
Benioff, H., Global strain accumulation and release as revealed by great earthquakes, Bull. Geol. Soc. Am., 62, 331-338, $1951 b$.

Benioff, H., Seismic evidence for crustal structure and tectonic activity, Geol. Soc. Am. Spec. Paper, 62, 61-74, 1955.

Ben-Menahem, A., and David G. Harkrider, Radiation patterns of seismic surface waves, $J$. Geophys. Res., 69, 2605-2620, 1964.

Brace, W. F., and T. D. Byerlee, Stick-slip as a mechanism for afterquakes, Science, 153, 990$992,1966$.

Brune, J. N., Seismic moment, seismicity and rate of slip along major fault zones, J. Geophys. Res., 79, 777-784, 1968.

Brune, J. N., and C. R. Allen, A low-stress-drop, low-magnitude earthquake with surface faulting: The Imperial, California, earthquake of March 4, 1966, Bull. Seismol. Soc. Am., 67, 501514, 1967.

Brune, J. N., A. Espinosa, and J. Oliver, Relative excitation of surface waves by earthquakes and underground explosions in the CaliforniaNevada region, J. Geophys. Res., 68, 3501-3513, 1963.

Brune, J. N., and Chi-Yu King, Excitation of mantle Rayleigh waves of period 100 seconds as a function of magnitude, Bull. Seismol. Soc. Am., 67, 1355-1365, 1967.

Burridge, R., and L. Knopoff, Body force equivalents for seismic dislocations, Bull. Seismol. Soc. $A m ., 54,1874-1888,1964$.

Burridge, R., and L. Knopoff, Model of theoretical seismicity, Bull. Seismol. Soc. Am., 67, 341-372, 1967.

Chinnery, M. A., The strength of the earth's crust under horizontal shear stress, J. Geophys. Res., 69, 2085-2089, 1964.

Harkrider, D. G., Surface waves in multilayered elastic media, 1, Rayleigh and Love waves from buried sources in a multi-layered elastic halfspace, Bull. Seismol. Soc. Am., 64, 627-679, 1964.

Iida, K., Earthquake energy and earthquake fault, J. Earthquake Sci. Nagoya Univ., 7, 98-107, 1959.

Iida, K., Earthquake magnitude, earthquake fault and source dimensions, J. Earthquake Sci. $\mathrm{Na}$ goya Univ., 13, 115-132, 1965.

Keylis-Borok, V. I., On estimation of the displacement in an earthquake source and of source dimensions, Ann. Geofisic. 12, 205-214, 1959.

King, Chi-Yu, and L. Knopoff, Stress drop in earthquakes, Bull. Seismol. Soc. Am., 58, 249257, $1968 a$.

King, Chi-Yu, and L. Knopoff, Model seismicity: Rupture parameters, stress and energy relations, J. Geophys. Res., 73, 1399-1406, $1968 b$.

Knopoff, L., Energy release in earthquakes, Geophys. J., 1, 44-52, 1958.

Maruyama, T., On the force equivalent of $\mathrm{dy}-$ namic elastic dislocations with reference to the earthquake mechanism, Bull. Earthquake Res. Inst. Tokyo Univ., 41, 467-486, 1963.

McEvilly, T. V., W. M. Bakun, K. B. Cassaday, The Parkfield California earthquakes of 1966, Bull. Seismol. Soc. Am., 67, 1221-1258, 1967.

Orowan, E., Mechanism of seismic faulting in rock deformation, A Symposium, Geol. Soc. Am. Mem., 79, 323-345, 1960.

Press, Frank, Dimensions of the source region for small shallow earthquakes, Proceedings of the VESIAC Conference on the Current Status and Future Progress for Understanding the Source Mechanism of Shallow Seismic Events in the 9 to 5 Magnitude Range, 1967.

Richter, C. F., Elementary Seismology, W. H. Freeman and Co., San Francisco, Calif., 1958.

Richter, C. F., J. M. Nordquist, V. Taylor, and C. R. Allen, Local bulletin of earthquakes in the southern California region, California Institute of Technology, Pasadena, 1967.

Smith, S. W., C. G. Sammis, and W. H. Jackson, Microearthquake source dimensions and energy release (abstract), Trans. Am. Geophys. Union, 48, 201, 1967.

Smith, S. W., and Max Wyss, Displacement on the San Andreas fault initiated by the 1966 Parkfield earthquake, in preparation, 1968.

Starr, A. T., Slip in a crystal and rupture in a solid due to shear, Proc. Cambridge Phil. Soc., 24, 489-500, 1928.

Sykes, L. R., Seismological evidence for transform faults, sea-floor spreading, and continental drift, in History of the Earth's Crust, edited by R. A. Phinney, Princeton University Press, Princeton, N. J., in press, 1968.

Tocher, D., Earthquake energy and ground breakage, Bull. Seismol. Soc. Am., 48, 147-153, 1958.

Tsuboi, C., Earthquake energy, earthquake volume, aftershock area, and strength of the earth's crust, J. Phys. Earth, 4, 63-66, 1956.

(Received January 25, 1968; revised March 18, 1968.) 